\section{Life In and Under the Antarctic Ice Sheets}

Shawn Doyle, Pierre Amato and Brent Christner

Louisiana State University.

sdoyle2@lsu.edu

\section{Introduction}

The discovery of viable microbial life in ancient glacial ice has opened up a plethora of questions related to how life can be sustained in such extreme environments. Cryo-microscopic analysis of lab prepared ice samples indicates that microbes are located in the small veins of water that exist between individual ice crystals. Crucial to these studies is to obtain an understanding of the physicochemical habitat for life through physiological and microscopic analysis.

Little is known about the biology of microorganisms that live in permanently cold environments despite the fact that $>80 \%$ of the biosphere (by volume) is below $5^{\circ} \mathrm{C}, 14 \%$ of the terrestrial surface is polar, and most of the biomass on the planet is microbial. Until about ten years ago, no one considered subglacial environments to be a possible habitat for microbial life. However, recent discoveries of viable microbial cells deep inside glacial ice and the sub-glacial environments have resulted in a new paradigm for tenacity of life on Earth. The discovery of this previously unknown habitat may also provide new hope in the search for extra-terrestrial life in the Martian polar ice caps or on Jupiter's moon Europa.

Recent studies of ancient glacial ice have shown that bacteria remain viable for hundreds of thousands of years while frozen. This is surprising as macromolecular damage (e.g., to DNA) would accumulate in the absence of metabolic activity through various mechanisms such as amino acid racemisation, DNA depurination and exposure to natural ionizing radiation.

While it is possible that such entrapped microbes have evolved to be particularly successful at surviving metabolic dormancy, it has been shown that they many are able to maintain a slow metabolic rate to repair macromolecular damage.

The Christner research group is currently studying various aspects of subzero biology with laboratory and field studies to examine the ability of bacteria in glaciated environments to metabolize and

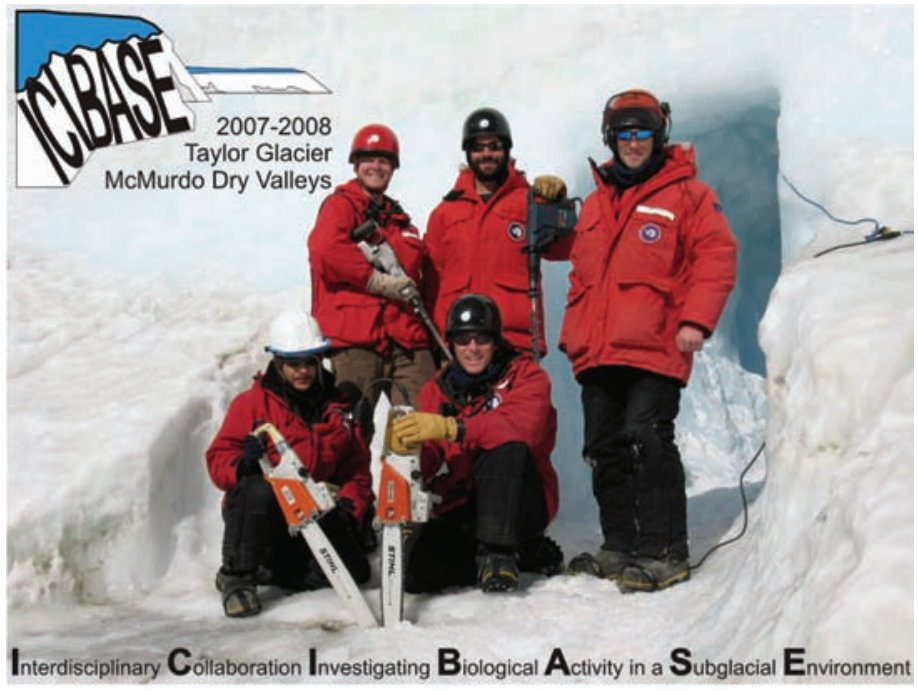

Fig 1, The ICIBASE team with their sample extraction tools. Back Row left to right: Tim Brox, Scott Montross, Shawn Doyle. Front Row: Pierre Amato, Brent Christner. respire $\mathrm{CO}_{2}$ within solid ice.

Our field-based experiments have taken members of our ICIBASE (Interdisciplinary Collaboration Investigating Biological Activity in a Subglacial Environment) team to Taylor Glacier in the McMurdo Dry Valleys of Antarctica. The goal is to extract and analyze samples from the base of the glacier to gather evidence that supports the hypothesis that micro-organisms living in the glacier are metabolically active.

\section{Sample Extraction}

Taylor Glacier is located $\sim 120 \mathrm{~km}$ from McMurdo Station - a scientific research station and the largest settlement on the continent. This outlet glacier is about $54 \mathrm{~km}$ long and was named by Captain Robert Falcon Scott after Griffith Taylor, geologist for the Western Journey Party of the British Antarctic Expedition (1910-13).

In order to extract the samples, our team had to cope with temperatures as low as $-20^{\circ} \mathrm{C}$ and wind speeds up to $110 \mathrm{kph}$. All supplies, equipment, and food were flown in by helicopter, requiring heavy logistical planning. The human body can easily burn in excess of $5000 \mathrm{kcal}$ per day when exposed to extreme cold (compared to an average of 2000kcal) making food delivery and consumption an important part of field work in Antarctica.

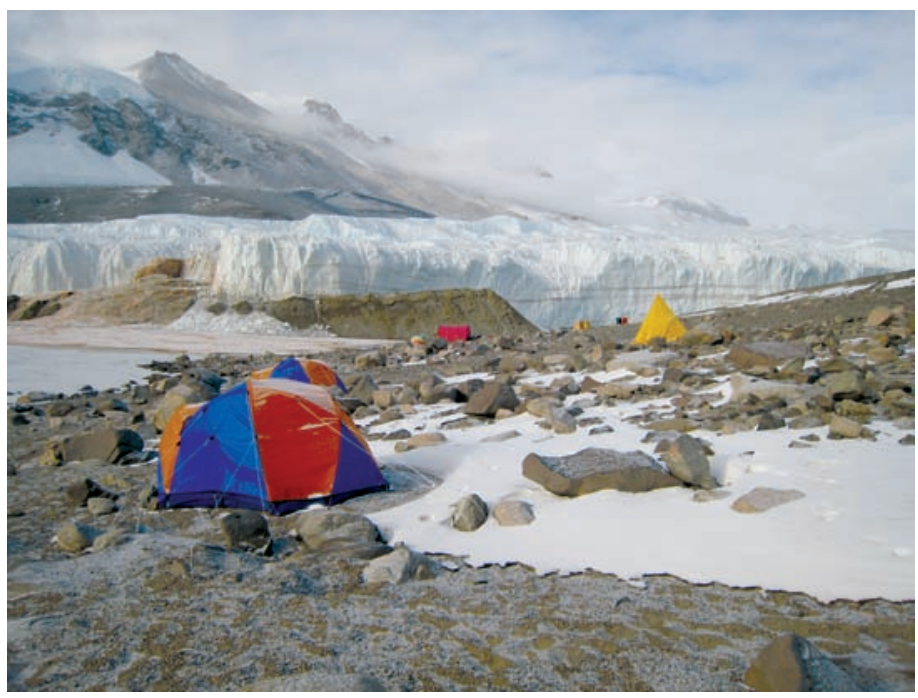

Fig 2, The field camp was located on the shore of Lake Bonney, a perennially ice covered lake at the terminus of the Taylor glacier.

The experimental site was located $2 \mathrm{~km}$ up valley from the field camp seen in figure 2 . The site was selected based on its relative ease of access and the stability of the glacial margin in order to return large amounts of sample from the field and minimize the risk of potentially deadly calving events.

Using chainsaws, figures $3-7$, a $\sim 14 \mathrm{~m}$ tunnel was constructed into the side of the glacier, after which a $5 \mathrm{~m}$ deep vertical shaft was excavated. Careful planning was necessary in the design and construction of the tunnel to allow samples to be retrieved from marginal areas of the glacier that were not folded and distorted as the result of glacier movement. The tunnel also needed to be angled $45^{\circ}$ upstream to align the profile of the tunnel with the direction of the ice flow.

The vertical shaft at the end of the tunnel exposed a large profile some $4 \mathrm{~m}$ in height that contained several stratified sedimentary layers as well as larger layers of more uniform clean ice. Three distinct types of ice were present in the profile: clean ice which 
$\Delta \Delta \Delta \Delta \Delta \Delta \Delta \Delta \Delta \Delta, \Delta \Delta \Delta-\Delta \Delta \Delta \Delta \Delta \Delta$ $\triangle \Delta \Delta \triangle \triangle \triangle \triangle \Delta \Delta \Delta$ IN THE WOods $\triangle \triangle \triangle \triangle$

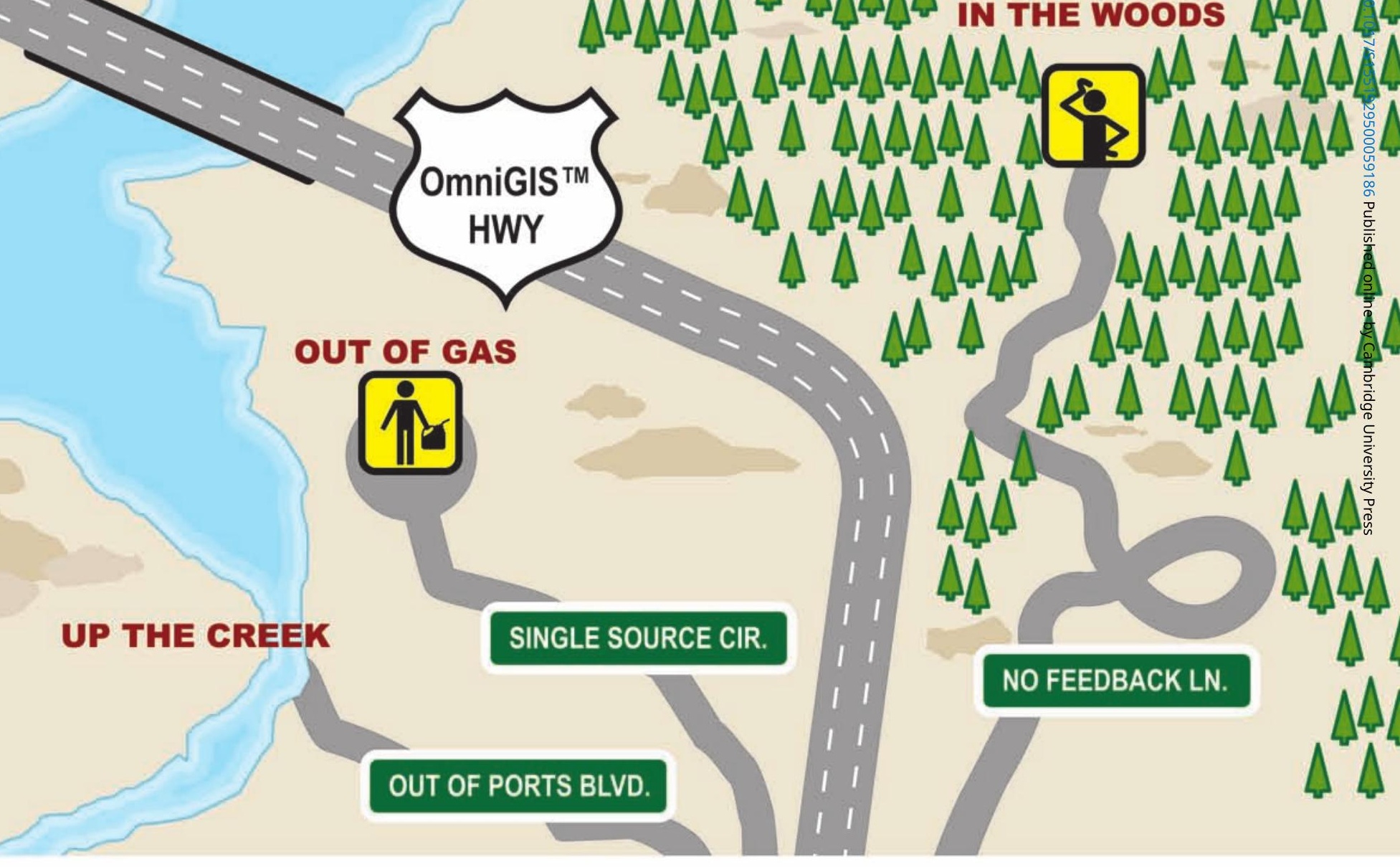

\section{Get There With the OmniGISTM}

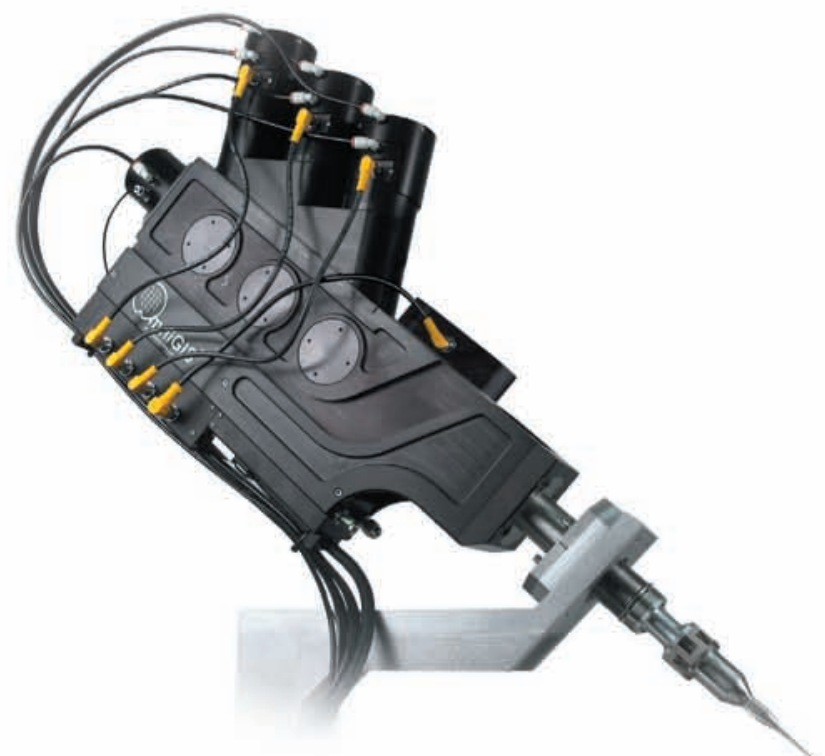

The NEW OmniGIS ${ }^{\mathbf{m}}$ provides an economical, smart and flexible platform for routine processes as well as for the exploration of innovative gas chemistries in the SEM or FIB.

The OmniGIS ${ }^{\mathrm{TM}}$ features:

- Three on-board precursors

- Single needle delivery

- Two external carrier/purge gas inputs

- Gas flow feedback control

- Programmable process flows

User-replaceable sources reduce downtime. Multiple gases on one port expand options. Feedback control supports automation. 


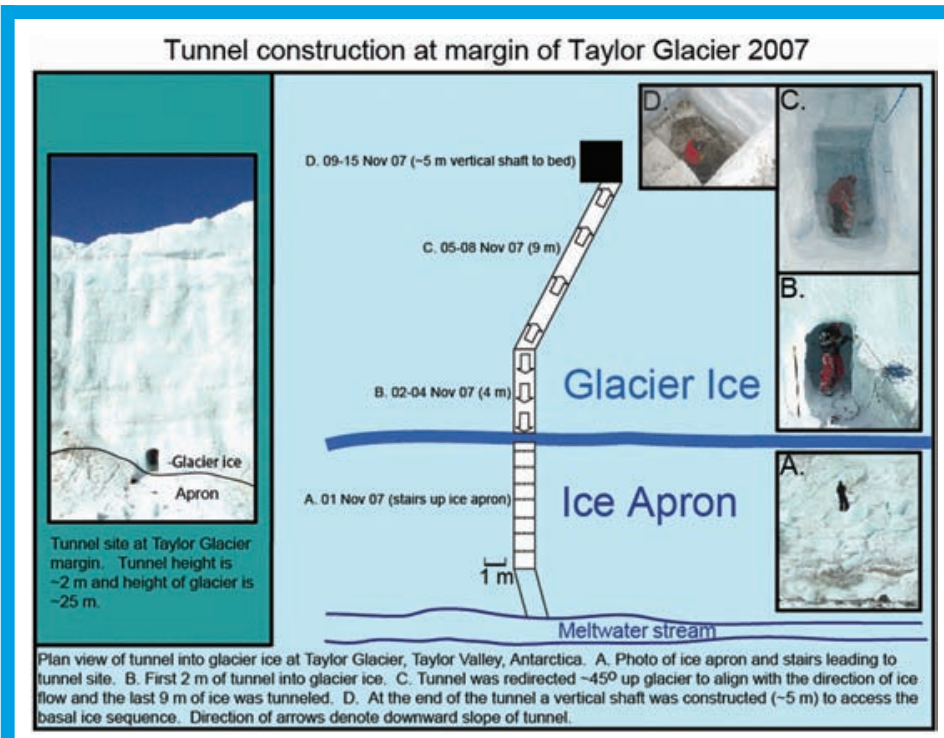

Fig 3, This tunnel construction figure is kindly provided by Scott Montross
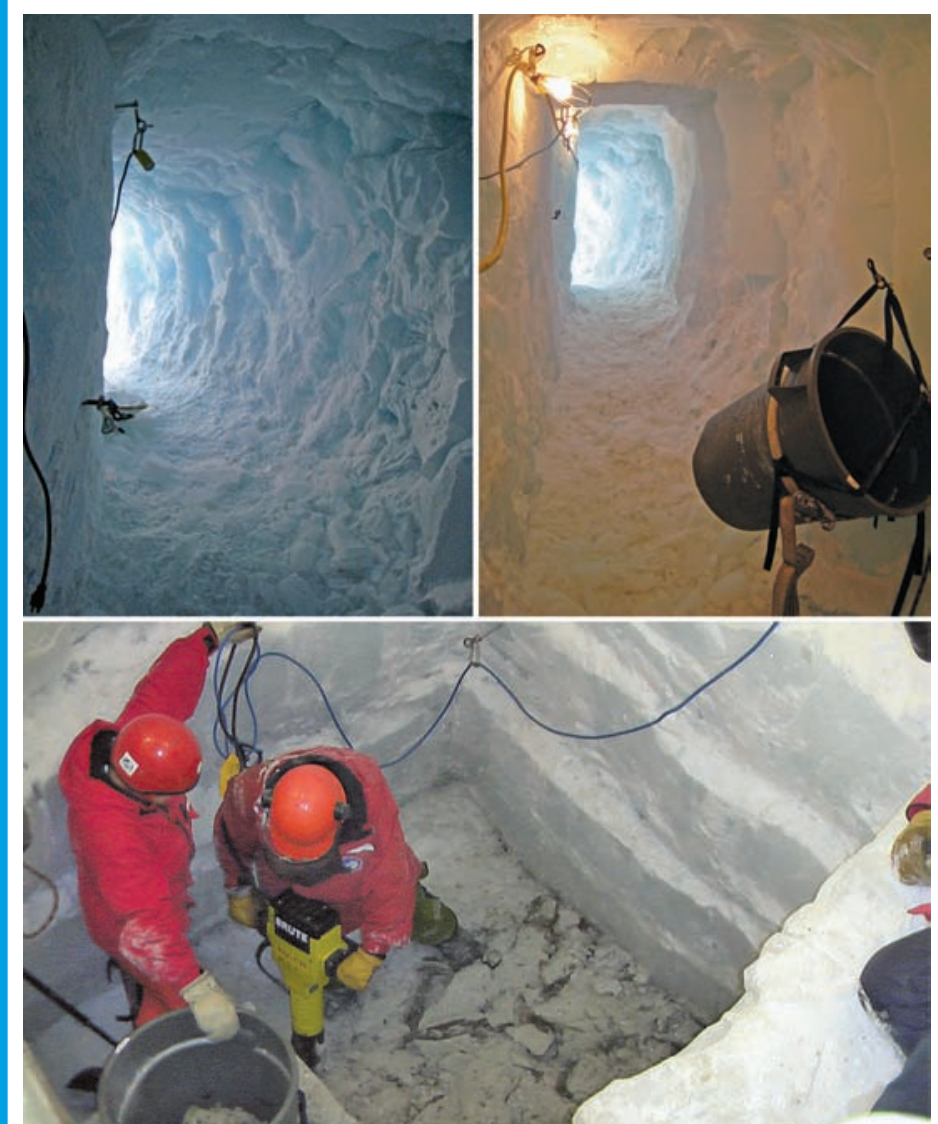

Fig 4, (upper left) Up-sloping initial $4 m$ of tunnel. Fig 5, (upper right) down-sloping $9 m$ portion of the tunnel. Fig 6, (bottom) $5 m$ shaft being dug.

had little to no sediment, stratified ice containing up to $20 \%$ (w/v) sediment, and basal massive ice containing up to $40 \%$ (w/v) sediment. The large amounts of sediments and their location in the glacier indicate that the material was incorporated during glacial flow from the bedrock.

The team removed a total of $\sim 1000 \mathrm{~kg}$ of ice samples from inside the Taylor glacier, which are now undergoing both biological and geochemical analysis at Louisiana and Montana State Universities.

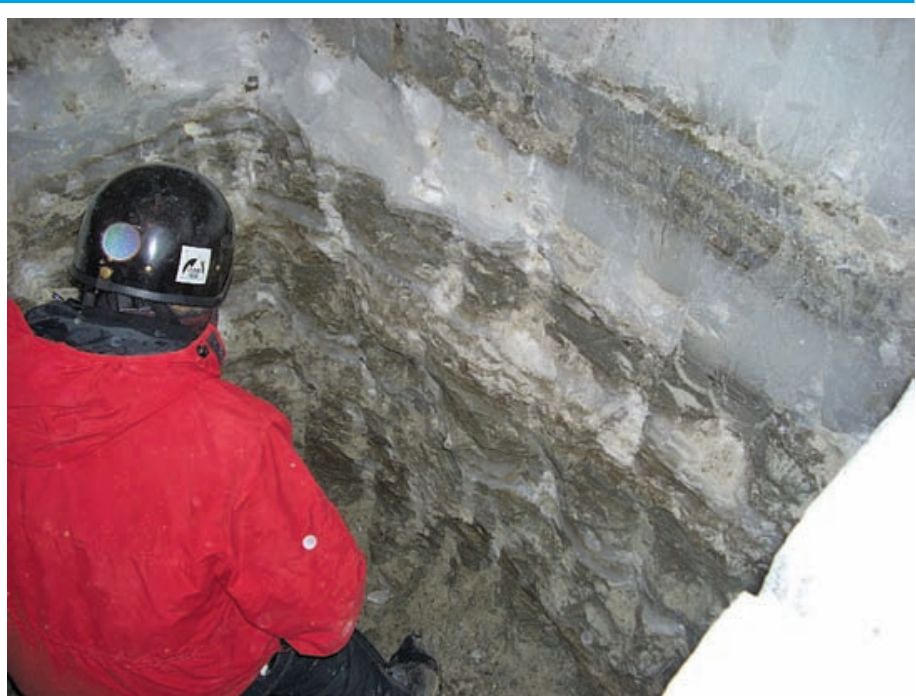

Fig 7, Stratified, sediment containing ice and basal ice at the glacier/ rock interface.

\section{Experimental studies}

There are numerous obstacles to overcome when studying active microbes entrapped with solid ice. Obviously, the extraction of samples from the glacier itself is difficult, but equally taxing is studying the cells under conditions and temperatures that closely mimic those they experience entrapped in glacier ice.

To visualize cells at temperatures germane to those in situ, we examined isolated glacier bacteria on an Olympus BX51-TRF fitted with Linkam's LTS350 microscopy stage that can maintain sample temperatures to within $0.1^{\circ} \mathrm{C}$ over a temperature range of $-196^{\circ} \mathrm{C}$ to $350^{\circ} \mathrm{C}$, figure 8.

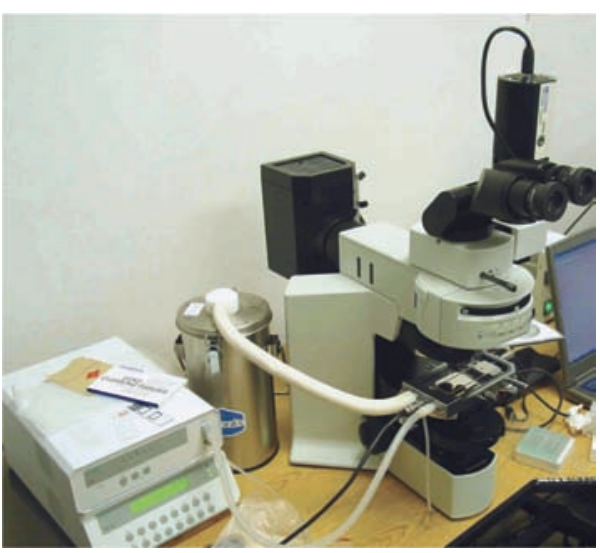

Fig 8, Olympus BX51-TRF fitted with the Linkham LTS350 thermal stage.
The stage consists of a large temperature controlled element with a platinum resistor sensor embedded close to the surface for accurate temperature measurements. The sample is simply mounted on a standard microscope slide in direct contact with the polished heating element and can be manipulated $15 \mathrm{~mm}$ in X and $\mathrm{Y}$ direction.

Additionally, the sample chamber is gas tight and has gas valves to control the environment inside the cell whether it is inert gas or humidity. A specially designed copper sample cover lid creates a uniform thermal environment for the sample without compromising the $\mathrm{X}, \mathrm{Y}$ manipulation.

Epi-fluorescence analysis was conducted after staining the cells with the SYBR-Gold DNA stain.

\section{A possible habitat for microorganisms in ice}

Liquid water is necessary for metabolic activity and even at very low temperatures some fraction of the water in ice is unfrozen. 


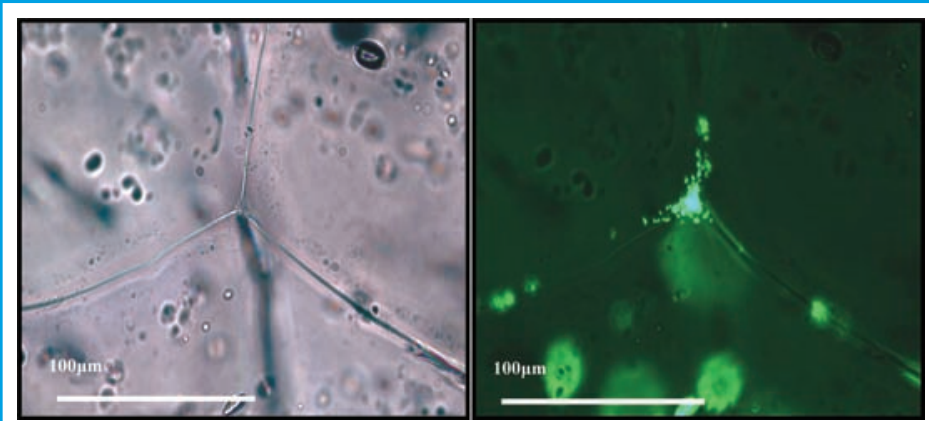

Fig 9, Exclusion of a Chryseobacterium into a triple junction in the ice at $-20^{\circ} \mathrm{C}$. (Left) a bright field image of the ice; (Right) the same field of view under epifluorescence. Cells were visualized using the DNA stain SYBR-Gold using an Olympus BX51-TRF microscope fitted with a Linkam LTS350 thermal stage.

As water freezes, impurities such as salts, minerals are excluded into small veins of water located between ice crystals. Cells are also partitioned into the aqueous phase of ice during freezing (see figure 9) and may be metabolically active in the liquid veins that exist between three-grain crystal boundaries in ice. This is known to occur in the brine channels present in sea ice, but has yet to be demonstrated in glacier ice.

The sediment-laden ice at Taylor Glacier contains elevated levels of cells and nutrients. Together with the presence of liquid water and anomalous concentrations of $\mathrm{O}_{2}$ and $\mathrm{CO}_{2}$ (gases consumed and produced during respiration, respectively) in the ice, our hypothesis is that these conditions are suitable for active microbial metabolism.

Gas anomalies (e.g., $\mathrm{CO}_{2}$ ) have also been documented in ice cores, which provide historical records of $\mathrm{CO}_{2}$ in the atmosphere. As such, there is now an active debate around the role of microbes

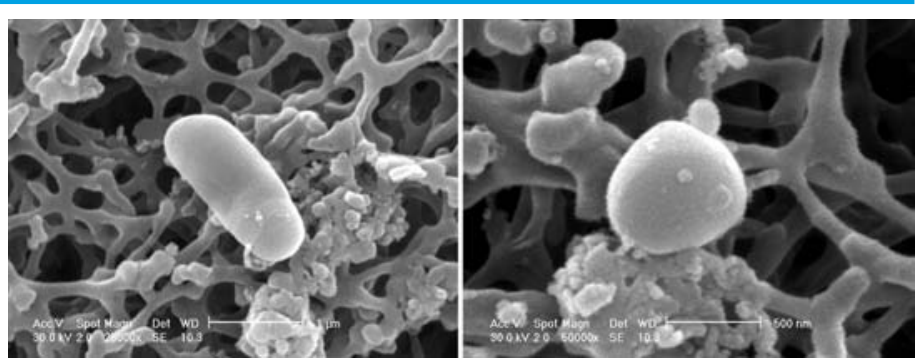

Fig 10, SEM images of glacial microbes.

within the ice and their effect on ice layers as unaltered recorders of past environmental conditions. At issue is the lack of a temperature constraint for microbial activity in ice and the consequences inherent to metabolism in the ice, e.g., gas composition alteration via aerobic or anaerobic respiration. Our work will provide valuable information that will important for diagnosing anomalous biogenic gases in ice cores and prevent under-estimations of greenhouse gases in ice cores. Other microscopy techniques are used in our studies. These include SEM and this is illustrated with examples of samples taken from the Taylor Dome, which flows into the Taylor Glacier described here, figure 10 .

Our research has substantially expanded the know limits for life in the biosphere and has extending the low temperature limits for life far below the freezing point of water. This work is also clearly relevant to astrobiological discussions concerning the longevity and survival of viable microbial life in icy extraterrestrial environments (e.g. Mars and Europa).

To find out more at our website www.brent.xner.net. We would like to thank the Montana State University team: Mark Skidmore, Scott Montross, and Timothy Brox for their wonderful work in the field. Photographs courtesy of the Christner Research Group.

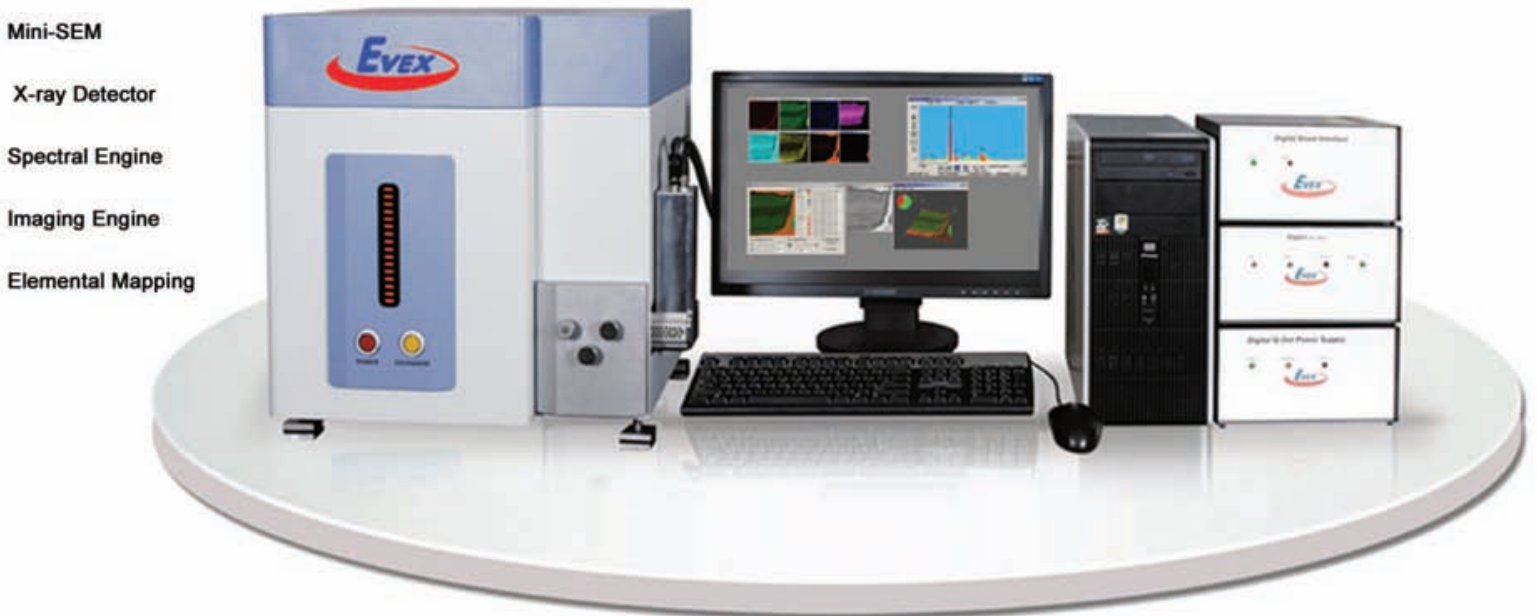

Scanning Electron Microscope 